
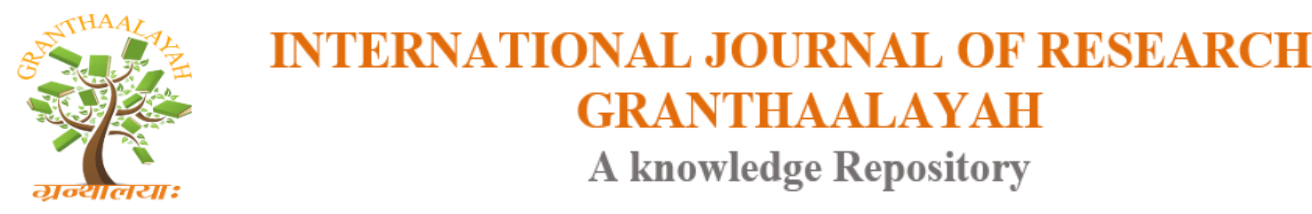

Science

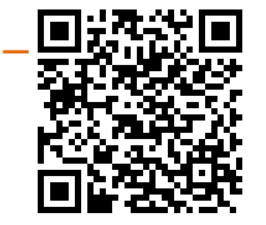

\title{
BANKS CAPACITOR COMPENSATION FOR CRITICAL NODAL DETECTION BY AUGMENTED RED WOLF OPTIMIZATION ALGORITHM
}

\author{
Dr. K. Lenin *1 \\ ${ }^{* 1}$ Professor, Department of EEE, Prasad V. Potluri Siddhartha Institute of Technology, Kanuru, \\ Vijayawada, Andhra Pradesh -520007, India
}

\begin{abstract}
In this paper Banks Capacitor Compensation for Critical Nodal Detections by Augmented Red Wolf Optimization Algorithm has been worked out. Projected ERWO algorithm hybridizes the wolf optimization (WO) algorithm with swarm based algorithm called as particle swarm optimization (PSO) algorithm. In the approach each Red wolf has a flag vector, and length is equivalent to the whole sum of numbers which features in the dataset of the wolf optimization (WO). Exploration capability of the projected Red wolf optimization algorithm has been enriched by hybridization of both WO with PSO. Efficiency of the projected Enriched Red wolf optimization (ERWO) is tested in standard IEEE 57 bus test system. Simulation study indicates Enriched Red wolf optimization (ERWO) algorithm performs well in tumbling the actual power losses.
\end{abstract}

Keywords: Reactive Power; Loss; Red Wolf Optimization.

Cite This Article: Dr. K. Lenin. (2018). "BANKS CAPACITOR COMPENSATION FOR CRITICAL NODAL DETECTION BY AUGMENTED RED WOLF OPTIMIZATION ALGORITHM." International Journal of Research - Granthaalayah, 6(10), 169-175. https://doi.org/10.29121/granthaalayah.v6.i10.2018.1175.

\section{Introduction}

Reactive power problem plays major role in improving secure \& economic of power system operation \& control. To determine the size, type, and location of capacitor banks to be installed on radial distribution feeders to achieve positive economic response is the objective of optimal capacitor placement problem. Loss reductions weighted against capacitors costs with constraints are in limits to obtain the economic benefits. A variety of methodologies [1-6] have been implemented to solve the problem, but difficulty found in handling the constraints. Now days various types of Evolutionary algorithms implemented to solve problem [7-19]. For last twenty years various types of programming and probabilistic based approach has been used to solve the problem. In this work Enriched Red wolf optimization (ERWO) algorithm has been implemented to work out the problem. Both Exploration \& Exploitation has been improved. In basic Wolf 
optimization algorithm (WO) [20], exploration spaces are missing the diversity and the highquality diversity is needed to upgrade the performance of the algorithm to find an optimal solution. Particle swarm optimization (PSO) [21] has good feature of exploration ability and it has been hybridized with Wolf optimization algorithm (WO) to produce an enriched version called as Enriched Red wolf optimization (ERWO). PSO will aid to form better preliminary population to WO. In standard IEEE 57 bus test system efficiency of Enriched Red wolf optimization (ERWO) algorithm has been evaluated. Results indicate that Enriched Red wolf optimization (ERWO) algorithm performs well in tumbling the actual power losses.

\section{Problem Formulation}

Reducing power loss, bus voltage with specified limits with minimized cost is the objective function of capacitor placement. Voltage limits are considered as constraints. Due to the capacitor placement the annual cost and power losses are given by,

$\operatorname{Minimize}\left\{F=Z_{P L} P_{L}+\sum_{j=1}^{N} Z_{c j} D_{j}\right\}$

Where F - total annual cost function (\$),

ZPL the annual cost per unit of power losses, $(\$ / \mathrm{KW}), \mathrm{PL}$ - total active power loss $(\mathrm{KW})$,

N- Number of buses.

Constraint of voltage is given as

$V_{i}^{\min } \leq V_{i} \leq V_{i}^{\max }$

\section{Red Wolf Optimization}

Red wolf optimization mimics the communal management and hunt deeds of Red wolves in nature. There are three fittest candidate solutions assumed as $\alpha, \beta$ and $\gamma$ to lead the population toward promising regions of the exploration space in each iteration of red wolf optimization. $\varphi$ is named for the rest of Red wolves and it will assist $\alpha, \beta$ and $\gamma$ to encircle, hunt, and attack prey, that is, to find Enriched solutions. In order to scientifically replicate the encompassing behavior of Red wolves, the following equations are proposed:

$\vec{G}=\left|\vec{F} \cdot \overrightarrow{Y_{P}}(t)-\vec{Y}(t)\right|$

$\vec{Y}(t+1)=\overrightarrow{Y_{P}}(t)-\vec{H} \cdot \vec{G}$

Where tindicates the current iteration, $\vec{H}=2 \vec{b} \cdot \overrightarrow{r_{1}}-\vec{b}, \vec{F}=2 \cdot \overrightarrow{r_{2}}, \widehat{Y_{P}}$ the position vector of the prey, $\vec{Y}$ is the position vector of a Red wolf, $\vec{b}$ is linearly decreased from 2.0 to 0 , and $\overrightarrow{r_{1}}$ and $\overrightarrow{r_{2}}$ are arbitrary vectors in $[0,1]$.

Hunting behavior of Red wolves are mathematically simulated by following equations, 
$\overrightarrow{G_{\alpha}}=\left|\overrightarrow{F_{1}}, \overrightarrow{Y_{\alpha}}-\vec{Y}\right|$

$\overrightarrow{G_{\beta}}=\left|\overrightarrow{F_{2}}, \overrightarrow{Y_{\beta}}-\vec{Y}\right|$

$\overrightarrow{G_{\gamma}}=\left|\overrightarrow{F_{3}}, \overrightarrow{Y_{\gamma}}-\vec{Y}\right|$

$\overrightarrow{Y_{1}}=\overrightarrow{Y_{\alpha}}-\overrightarrow{H_{1}} \cdot \overrightarrow{G_{\alpha}}$

$\overrightarrow{Y_{2}}=\overrightarrow{Y_{\beta}}-\overrightarrow{H_{2}} \cdot \overrightarrow{G_{\beta}}$

$\overrightarrow{Y_{3}}=\overrightarrow{Y_{\gamma}}-\overrightarrow{H_{3}} \cdot \overrightarrow{G_{\gamma}}$

$\vec{Y}(t+1)=\frac{\overrightarrow{Y_{1}}+\overrightarrow{Y_{2}}+\overrightarrow{Y_{3}}}{3}$

In this work, a new Enriched Red wolf optimization (ERWO) algorithm is proposed to solve reactive power dispatch problem \& the position of a Red wolf was updated \& the following equation is used to discrete the position.

flag $_{i, j}=\left\{\begin{array}{lc}1 & Y_{i, j}>0.50 \\ 0 & \text { otherwise }\end{array}\right.$

Where $\mathrm{i}$, indicates the jth position of the ith Red wolf, flag $_{i, j}$ is features of the wolf.

\section{Particle Swarm Optimization}

In Particle swarm optimization (PSO) algorithm the positions and velocities of the Particles are modernized as follows:

$v_{t+1}^{i}=\omega_{t} \cdot v_{t}^{i}+c g_{1} \cdot R m_{1} \cdot\left(m_{t}^{i}-y_{t}^{i}\right)+c g_{2} \cdot R m_{2} \cdot\left(m_{t}^{g}-y_{t}^{i}\right)$

$y_{t+1}^{i}=y_{t}^{i}+v_{t+1}^{i}$

The current position of particle is $\mathrm{y}_{\mathrm{t}}^{\mathrm{i}} \&$ search velocity is $\mathrm{v}_{\mathrm{t}}^{\mathrm{i}}$. Global best-found position is. $\mathrm{m}_{\mathrm{t}}^{\mathrm{g}}$. In uniformly distributed interval $(0,1) \mathrm{Rm}_{1} \& \mathrm{Rm}_{2}$ are arbitrary numbers. Where $\mathrm{cg}_{1}$ and $\mathrm{cg}_{2}$ are scaling parameters. $\omega_{t}$ is the particle inertia. The variable $\omega_{t}$ is modernized as

$\omega_{t}=\left(\omega_{\max }-\omega_{\min }\right) \cdot \frac{\left(t_{\max }-t\right)}{t_{\max }}+\omega_{\min }$

Maximum and minimum of $\omega_{t}$ is represented by $\omega_{\max }$ and $\omega_{\min }$; maximum number of iterations

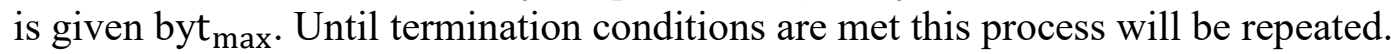




\section{Enriched Red Wolf Optimization (ERWO) Algorithm for Solving Optimal Reactive Power Dispatch Problem}

In this approach red wolves $\alpha, \beta$ and $\gamma$ determine the position of the prey. $\vec{H}=2 \overrightarrow{\mathrm{b}} \cdot \overrightarrow{\mathrm{r}_{1}}-\overrightarrow{\mathrm{b}}$ directs the exploration \& exploitation process by reducing the value from 2 to 0 . When $|\vec{H}|<1$ it converged towards the prey\& If $|\overrightarrow{\mathrm{H}}|>1$ diverged away. The first best Minimum loss and variables are accumulated as" $\alpha$ "position, score $\&$ as like second best, third best accumulated as " $\beta$ " and " $\gamma$ " position \& score.

Commence

Initialize the parameters

Initialize $b, \vec{H}$ and $\vec{F}$; beginning positions of Red wolves has been stimulated.

$\mathrm{i}=1$ : population size

$\mathrm{j}=1: \mathrm{n}$

When $(i, j)>0.500$

(i) $=1$;

Else

(j) $=0$;

End if

End for

Work out the maximum fitness of Red wolves as follows,

Primary maximum fitness of the Red wolf is designated as " $\alpha$ "

Second maximum fitness of the Red wolf is designated as " $\beta$ "

Third maximum fitness of the Red wolf is designated as " $\gamma$ "

While $\mathrm{k}<$ maximum iteration

For $\mathrm{i}=1$ : population size

Exact Location of the existing Red wolf has been revised periodically

End for

For $\mathrm{i}=1$ : population size

For $\mathrm{i}=1: \mathrm{n}$; If $(\mathrm{i}, \mathrm{j})>0.500$

(j) $=1$;

Else

(j) $=0$;

End if

End for

Sporadically revise the values of $b, \overrightarrow{\mathrm{H}}$ and $\overrightarrow{\mathrm{F}}$;

At this stage Fitness of Red wolves has been calculated

The assessment of red wolves " $\alpha$ ", $\beta$ " and " $\gamma$ "has to be revised

$\mathrm{k}=\mathrm{k}+1$;

End while

Re-examine the value of" $\alpha$ "as the optimal characteristic division;

End 


\section{Simulated Outcomes}

The Enriched Red Wolf Optimization (ERWO) has been applied in standard IEEE 57 bus system. The base voltage each bus taken as $135 \mathrm{kV}$. In primary case Enriched Red Wolf Optimization (ERWO) has been applied \& table 1 shows the critical busses \& value of the capacitor. Table 2 shows the various parameters values before $\&$ after placement of the capacitor. Real power loss $\&$ reactive power value for various approach (Brahim GASBAOUI et al.2011) has been compared in table 3. After application of Enriched Red Wolf Optimization (ERWO) power losses are decreased by 23.797 reactive power injected into the electrical distribution system are diminished by 14.82 $\%$.

Table 1: capacitor value in critical buses

\begin{tabular}{|l|l|}
\hline Number of critical buses & Value of capacitor [MVAR] \\
\hline 10 & 3.89 \\
\hline 19 & 1.98 \\
\hline 21 & 3.02 \\
\hline 28 & 3.12 \\
\hline 32 & 4.99 \\
\hline 33 & 6.97 \\
\hline 52 & 1.02 \\
\hline
\end{tabular}

Table 2: key parameters value before \& after placement of capacitors

\begin{tabular}{|l|l|l|}
\hline & $\begin{array}{l}\text { Value - before placement of } \\
\text { optimal capacitor }\end{array}$ & $\begin{array}{l}\text { Value - after placement of optimal } \\
\text { capacitor }\end{array}$ \\
\hline $\begin{array}{l}\text { Value of real } \\
\text { Power loss in MW }\end{array}$ & 17.35 & 13.98 \\
\hline $\begin{array}{l}\text { Minimum } \\
\text { Voltage value in } \\
\text { per unit }\end{array}$ & 0.918 & 0.956 \\
\hline $\begin{array}{l}\text { Value of Reactive } \\
\text { power [MVAR] }\end{array}$ & 274.892 & 234.590 \\
\hline
\end{tabular}

Table 3: comparison of Real \& reactive power values

\begin{tabular}{|l|l|l|}
\hline Technique & Real Power Loss In MW & Reactive Power In MVAR \\
\hline $\begin{array}{l}\text { METHOD QN-OPF (Brahim } \\
\text { GASBAOUI Et Al.2011) }\end{array}$ & 17.16 & - \\
\hline $\begin{array}{l}\text { METHOD ACO-OPF (Brahim } \\
\text { GASBAOUI Et Al.2011) }\end{array}$ & 17.96 & - \\
\hline $\begin{array}{l}\text { METHOD MAT POWER } \\
\text { (Brahim GASBAOUI Et Al.2011) }\end{array}$ & 16.51 & 270.56 \\
\hline $\begin{array}{l}\text { METHOD FLC-HSO (Brahim } \\
\text { GASBAOUI Et Al.2011) }\end{array}$ & 15.29 & 239.27 \\
\hline $\begin{array}{l}\text { METHOD FLC-GAO (Brahim } \\
\text { GASBAOUI Et Al.2011) }\end{array}$ & 14.19 & 235.14 \\
\hline $\begin{array}{l}\text { PROPOSED ERWO (Brahim } \\
\text { GASBAOUI Et Al.2011) }\end{array}$ & 12.98 & 232.86 \\
\hline
\end{tabular}




\section{Conclusion}

Enriched Red wolf optimization (ERWO) approach effectively solved the problem. Exploration \& Exploitation has been considerably improved through the proposed methodology. Proposed technique has been tested in standard IEEE 57 bus test system. Comparison of the real power loss has been done along with reactive power values.

\section{References}

[1] K. Y. Lee, et al, "Fuel-cost minimisation for both real and reactive-power dispatches," Proceedings Generation, Transmission and Distribution Conference, vol/issue: 131(3), pp. 85-93, 1984.

[2] N. I. Deeb, et al., "An efficient technique for reactive power dispatch using a revised linear programming approach," Electric Power System Research, vol/issue: 15(2), pp. 121-134, 1988.

[3] M. R. Bjelogrlic, M. S. Calovic, B. S. Babic, et. al.," Application of Newton's optimal power flow in voltage/reactive power control", IEEE Trans Power System, vol. 5, no. 4, pp. 1447-1454, 1990.

[4] S. Granville, "Optimal reactive dispatch through interior point methods," IEEE Transactions on Power System, vol/issue: 9(1), pp. 136-146, 1994.

[5] N. Grudinin, "Reactive power optimization using successive quadratic programming method," IEEE Transactions on Power System, vol/issue: 13(4), pp. 1219-1225, 1998.

[6] Wei Yan, J. Yu, D. C. Yu and K. Bhattarai," A new optimal reactive power flow model in rectangular form and its solution by predictor corrector primal dual interior point method", IEEE Trans. Pwr. Syst., vol.21, no.1, pp.61-67, 2006.

[7] Aparajita Mukherjee, Vivekananda Mukherjee, "Solution of optimal reactive power dispatch by chaotic krill herd algorithm", IET Gener. Transm. Distrib, , Vol. 9, Issue. 15, pp. 2351-2362, 2015.

[8] $\mathrm{Hu}, \mathrm{Z}$., Wang, X. \& Taylor, G. Stochastic optimal reactive power dispatch: Formulation and solution method. Electr. Power Energy Syst., vol. 32, pp. 615-621. 2010.

[9] Mahaletchumi A/P Morgan, Nor Rul Hasma Abdullah, Mohd Herwan Sulaiman, Mahfuzah Mustafa and Rosdiyana Samad, "Computational intelligence technique for static VAR compensator (SVC) installation considering multi-contingencies (N-m)", ARPN Journal of Engineering and Applied Sciences, VOL. 10, NO. 22, DECEMBER 2015.

[10] Mohd Herwan Sulaiman, Zuriani Mustaffa, Hamdan Daniyal, Mohd Rusllim Mohamed and Omar Aliman, "Solving Optimal Reactive Power Planning Problem Utilizing Nature Inspired Computing Techniques", ARPN Journal of Engineering and Applied Sciences, VOL. 10, NO. 21, , pp.97799785. NOVEMBER 2015

[11] Mohd Herwan Sulaiman, Wong Lo Ing, Zuriani Mustaffa and Mohd Rusllim Mohamed, "Grey Wolf Optimizer for Solving Economic Dispatch Problem with Valve-Loading Effects", ARPN Journal of Engineering and Applied Sciences, VOL. 10, NO. 21, pp. 9796-9801, NOVEMBER 2015.

[12] Pandiarajan, K. \& Babulal, C. K., "Fuzzy harmony search algorithm based optimal power flow for power system security enhancement". International Journal Electric Power Energy Syst., vol. 78, pp. 72-79. 2016.

[13] Mustaffa, Z., Sulaiman, M.H., Yusof, Y., Kamarulzaman, S.F., "A novel hybrid metaheuristic algorithm for short term load forecasting", International Journal of Simulation: Systems, Science and Technology, Volume 17, Issue 41, Pages 6.1-6.6. 2017.

[14] Sulaiman, M.H., Mustaffa, Z., Mohamed, M.R., Aliman, O., "An application of multi-verse optimizer for optimal reactive power dispatch problems", International Journal of Simulation: Systems, Science and Technology, Volume 17, Issue 41, Pages 5.1-5.5. 2017.

[15] Mahaletchumi A/P Morgan, Nor Rul Hasma Abdullah, Mohd Herwan Sulaiman,Mahfuzah Mustafa and Rosdiyana Samad, "Multi-Objective Evolutionary Programming (MOEP) Using 
Mutation Based on Adaptive Mutation Operator (AMO) Applied For Optimal Reactive Power Dispatch", ARPN Journal of Engineering and Applied Sciences, VOL. 11, NO. 14, JULY 2016.

[16] Rebecca Ng Shin Mei, Mohd Herwan Sulaiman, Zuriani Mustaffa, "Ant Lion Optimizer for Optimal Reactive Power Dispatch Solution", Journal of Electrical Systems, "Special Issue AMPE2015", pp. 68-74.2016.

[17] Mahaletchumi Morgan, Nor Rul Hasma Abdullah, Mohd Herwan Sulaiman, Mahfuzah Mustafa, Rosdiyana Samad, "Benchmark Studies on Optimal Reactive Power Dispatch (ORPD) Based Multi-objective Evolutionary Programming (MOEP) Using Mutation Based on Adaptive Mutation Adapter (AMO) and Polynomial Mutation Operator (PMO)", Journal of Electrical Systems, 12-1, 2016.

[18] Rebecca Ng Shin Mei, Mohd Herwan Sulaiman, Zuriani Mustaffa, Hamdan Daniyal, "Optimal Reactive Power Dispatch Solution by Loss Minimization using Moth-Flame Optimization Technique”, Applied Soft Computing, Volume 59, October, Pages 210-222, 2017.

[19] M. Kaedi, "Fractal-based Algorithm: A New Metaheuristic Method for Continuous Optimization", International Journal of Artificial Intelligence, vol. 15, no. 1, pp. 76-92, 2017.

[20] A. Kaveh and F. Shokohi, "Application of Grey Wolf Optimizer in design of castellated beams," Asian Journal of Civil Engineering, vol. 17, no. 5, pp. 683-700, 2016.

[21] Kennedy, J. and R.C. Eberhart, 1995. "Particle swarm optimization", Proceeding of IEEE International Conference on Neural Networks, Perth, Australia, pp: 1942-1948.

[22] Brahim GASBAOUI and Boumediène ALLAOUA (2009), Ant Colony Optimization Applied on Combinatorial Problem for Optimal Power Flow Solution Leonardo Journal of Sciences ISSN 1583-0233 Issue 14, p. 1-17.

[23] Abdelfatah NASRI1, Brahim GASBAOUI (2011), novel power flow problem solutions method's based on genetic algorithm optimization for banks capacitor compensation using an fuzzy logic rule bases for critical nodal detections, power engineering and electrical engineering ,9(4), pp;150156

\footnotetext{
*Corresponding author.

E-mail address: gklenin@ gmail.com
} 